\title{
Novel insights in Noonan syndrome
}

\author{
Giulia Dodi and Francesco Chiarelli* \\ Department of Paediatrics, University of Chieti, Italy
}

\begin{abstract}
Noonan syndrome is an inherited developmental disorder, classically identified by typical appearance, short stature, and cardiologic impairment. Nowadays it is recognized as part of RASopathies, i.e. a group of genetic disorders affecting the RAS-MAPK pathway. Diagnosis and clinical management of Noonan syndrome are challenging for the general paediatrician and children do require thorough multidisciplinary assessments throughout growth. Particularly, they must be referred to both paediatric endocrinologists and paediatric cardiologists. Prompt diagnosis is possible and genetic counselling for affected families is essential. This paper reviews clinical features and current treatment guidelines of Noonan syndrome in order to allow general paediatricians to better care children and adolescents with Noonan syndrome and to ensure a proper multidisciplinary approach.
\end{abstract}

\section{Introduction}

Noonan syndrome (MIM 163950) (NS) is a genetic developmental disorder, historically identified by typical physical appearance associated to short stature and congenital heart defects. Jaqueline Noonan, a paediatric cardiologist, was the first to characterize the syndrome: she identified nine children with remarkably similar faces, short stature, significant chest deformities and pulmonary stenosis. Initially, NS was mixed up with Turner syndrome; the fact that males could be affected and reports of normal karyotypes helped to separate these two entities. In 1994, Noonan syndrome was mapped to 12q24.1 and genetic heterogeneity was documented. In 2001 Tartaglia and colleagues identified the first gene (PTPN11) associated to NS [1]. To date, pathogenetic mutations have been demonstrated in several genes across RAS-MAPK signal transduction pathway (mitogenactivated protein kinase), that is an important regulator of cell growth, differentiation and senescence [2]. Gradually, other syndromes related to NS have been described: NS with multiple lentigo or LEOPARD syndrome (MIM 151100), Noonan-like syndrome with loose anagen hair (MIM 607721), Costello syndrome (MIM 218040), cardio-faciocutaneous syndrome (MIM 115150), type I neurofibromatosis (MIM 162200), and Legius syndrome (MIM 611431) [2,3]. Currently, NS and related disorders are collectively named RASopathies, i.e. a group of diseases related by constitutional dysregulation of the RAS signalling pathway and phenotype resembling NS [3]. Cardiac involvement, impaired growth, intellectual disabilities, predisposition to cancer and ectodermal, muscle and skeletal defects are variably represented. An extensive description of all RASopathies goes beyond the intent of this paper: we will provide a general overview of NS as a paradigm for this group of pathologies. In fact, the aim of this paper is to summarize the general characteristics of NS with special attention to cardiac disease and GH therapy; people with NS and other RASopathies require prompt diagnosis and multidisciplinary interventions at different stages of their lives.

\section{Epidemiology}

With a cumulative incidence of about 1 per 1000 live births, RASopathies represent one of the largest groups of developmental disorders [2]. The incidence of NS is estimated to be 1 case per 1000 to 1 case per 2500 live births [1,4]. It is the most common cause of congenital heart disease after trisomy 21.

\section{Pathogenesis}

NS is a genetic pathology due to sporadic or inherited mutations, with normal karyotype; most cases are transmitted in an autosomal dominant manner and for these reasons males and females are equally affected. As similar autosomal dominant disorders, a significant percentage of cases result from de novo mutations. NS is characterized by incomplete penetrance: parents can be affected by mild forms. In addition, it seems that the mother is more often the transmitting parent: it depends on normal pubertal development in affected females, while affected males usually present cryptorchidism [5]. As mentioned, pathogenetic mutations are part of RAS MAPK signal transduction pathway. In addition to PTPN11, that accounts for approximatively $50 \%$ of mutations, pathogenetic mutations have been demonstrated in SOS1, RAF1, KRAS, NRAS, SHOC2, CBL, BRAF, SOS2, RIT1, RRAS, RASA2, SPRY1, LZTR1, MAP3K8, MYST4, and A2ML1 [2]. PTPN11, SOS1, RAF1 and RIT1 cover $93 \%$ of reported mutations. However, in $20-30 \%$ of all patients with NS, genetic mutations have not been identified [6]. PTPN11 (protein tyrosine phosphatase non-receptor type 11) gene encodes for SHP-2, a tyrosine phosphatase, that is involved in several developmental processes such as limb development, semilunar valvulogenesis, haemopoietic cell differentiation and mesodermal patterning and is widely expressed in several tissues such as heart, muscles and brain [7]. PTPN11 mutations result in a gain of function of SHP-2. There are no phenotypic features exclusive to a specific genotype, anyway genotype-phenotype correlations may be useful since there are significant differences in the risk of various NS manifestations based on the causative gene (Table 1). For instance, NS type 1 (MIM 163950), due to PTPN11 mutations, is characterized

*Correspondence to: Francesco Chiarelli, Department of Paediatrics, University of Chieti, Chieti, Italy, Tel: +39 0871 358015; Fax: + 390871 574538; E-mail: chiarelli@unich.it

Key words: general paediatrician, Noonan syndrome, short stature

Received: April 10, 2020; Accepted: April 24, 2020; Published: April 29, 2020 
Table 1. Genotype phenotype correlations in Noonan Syndrome.

\begin{tabular}{|c|c|c|c|}
\hline Phenotype & Gene & Location & Inheritance \\
\hline NS1 & PTPN11 & $12 \mathrm{q} 24.13$ & AD \\
\hline NS2 & LZTR1 & $22 \mathrm{q} 11.21$ & AR \\
\hline NS3 & KRAS & $12 \mathrm{p} 12.1$ & AD \\
\hline NS4 & SOS1 & $2 \mathrm{p} 22.1$ & AD \\
\hline NS5 & RAF1 & $3 \mathrm{p} 25.2$ & AD \\
\hline NS6 & NRAS & $1 \mathrm{p} 13.2$ & AD \\
\hline NS7 & BRAF & $7 \mathrm{q} 34$ & AD \\
\hline NS8 & RIT1 & $1 \mathrm{q} 22$ & AD \\
\hline NS9 & SOS2 & $14 \mathrm{q} 21.3$ & AD \\
\hline NS10 & LZTR1 & $22 \mathrm{q} 11.21$ & AD \\
\hline NS12 & MRAS & $3 \mathrm{q} 22.3$ & AD \\
\hline NS13 & RRAS2 & $11 \mathrm{p} 15.2$ & AD \\
\hline
\end{tabular}

*PTPN11 Protein Tyrosine Phosphatase Non-Receptor Type 11, LZTR1 Leucine Zipper like Transcription Regulator 1, KRAS KRAS Proto-Oncogene, GTPase, SOS1 SOS Ras/Rac Guanine Nucleotide Exchange Factor 1, RAF1 Raf-1 Proto-Oncogene, Serine/ Threonine Kinase, NRAS, BRAF B-Raf Proto-Oncogene, Serine/Threonine Kinase, RIT1 Ras Like Without CAAX 1, SOS2 SOS Ras/Rho Guanine Nucleotide Exchange Factor 2, MRAS Muscle RAS Oncogene Homolog, RRAS2 RAS Related 2. [8].

by frequent pulmonary stenosis and atrial septal abnormality, shorter stature, lower insulin growth factor-1 (IGF1) levels, more bleeding diathesis and juvenile myelomonocytic leukaemia. Whereas, in NS type 3 (MIM 609942), due to KRAS mutations, hypertrophic cardiomyopathy and naevi, lentigo, and café au lait spots are typical $[2,8]$.

\section{Clinical presentation}

NS is a clinically heterogeneous disorder with multiple congenital malformations; it includes dysmorphic facial features, short stature, congenital heart diseases and parenchymal abnormalities and comorbidities. The diagnosis of NS is historically based on clinical findings using the scoring system by van der Burgt (1997). Anyway, the distinctive phenotypic triad is made up by facial features, short stature and cardiopathies $[9,10]$.

\section{Physical appearance}

Facial and musculoskeletal features most often lead to the diagnosis of Noonan syndrome. The facial appearance is most characteristic in infancy and early-to-middle childhood and becomes subtle in adulthood [9]. Newborns present tall forehead, hypertelorism with down-slanting palpebral fissures, low-set, posteriorly rotated ears with a thickened helix, a deeply grooved philtrum with high, wide peaks to the vermilion border of the upper lip and a short neck with excess nuchal skin and low posterior hairline. They have a triangular shape face. Infants have prominent eyes, with horizontal palpebral fissures, hypertelorism and full or ptotic upper eyelids; nose has a depressed root, wide base and bulbous tip. In childhood, facial appearance is often lacking in affect or expression. By adolescence, facial shape is an inverted triangle, wide at the forehead and tapering to a pointed chin. Eyes are less prominent and features are sharper; the neck lengthens, accentuating skin webbing or prominence of the trapezius muscle. In the older adult, nasolabial folds are prominent, and the skin appears transparent and wrinkled [8-11]. Skin abnormalities are common: follicular keratosis over extensor surfaces and face is characteristic of NS spectrum, also café au lait spots and lentigo are more frequent than in the general population [8]. A characteristic pectus deformity of the chest, with pectus carinatum superiorly and pectus excavatum inferiorly, is seen in most individuals. In addition, nipples are widespaced and low-set and rounded shoulders are common. Joint laxity is present in more than half of patients. Scoliosis is reported in $10 \%$ to
15\%. Less common spinal abnormalities include kyphosis, spina bifida, vertebral and rib abnormalities and genu valgum. Talipes equinovarus, radioulnar synostosis, cervical spine fusion and joint contractures were reported, too [12].

\section{Short stature}

A cardinal feature of NS, which can lead to diagnosis, is postnatal proportionate short stature, reported in $80 \%$ of patients. In fact, prenatal growth is classically normal, with birth weight and body length in the normal range. NS patients could present feeding difficulties, justifying enteral nutrition in one-fifth of infants. This period of failure to thrive is self-limited [9]. Postnatal growth failure may appear from the first year of life. The mean height follows the lower limit of the normal population (third percentile or -2 standard deviation score SDS) until the age of puberty, after which it declines further as a result of delayed puberty and attenuated pubertal growth spurts. Since bone maturity is usually delayed, prolonged growth into the 20 s is possible. Anyway, the final adult height is around -2SDS in both sexes; it is estimated 161-167 $\mathrm{cm}$ in males and 150-155 $\mathrm{cm}$ in females [13]. Specific growth charts are available and should be used in growth assessment of these patients [12]. To date, the primary cause of short stature in NS is unclear. For instance, insulin like growth factor 1 (IGF-1) concentrations are as low or low-normal in patients with PTPN11 mutations [14-16]. Anyway, the role of growth hormone in these children is still under study and is being disputed.

\section{Neuropsychological development}

Early developmental milestones may be delayed in NS infants, partly due to joint hyperextensibility and hypotonia, frequently described in these children. First words average age is around 15 months; this delay may be related to articulation deficiency, that is relatively common, hearing loss, or perceptual motor disabilities. During school-age about $50 \%$ of children present coordination disorders $[17,18]$. Individuals with NS have mildly lowered intellectual abilities, with IQ scores below 70 in $6 \%-23 \%$ of patients. Around a quarter of children affected by NS have learning disabilities and some of them require special education [17]. Attention and executive functioning seem to be impaired and autism spectrum disorders are more prevalent than in the general population [19].

\section{Cardiac abnormalities}

The prevalence of cardiovascular disease in Noonan syndrome is about $80-90 \%[9,12]$. The spectrum of cardiac anomalies is wide, including pulmonary valve stenosis (PVS) and hypertrophic cardiomyopathy, atrial septal defect (ASD), atrioventricular canal defect (AVCD), mitral valve anomalies, aortic coarctation, tetralogy of Fallot, ventricular septal defect (VSD) and aortic root dilatation. Atypical electrocardiographic patterns are present in approximately $50 \%$ of patients [20-22]. PVS represents $60-70 \%$ of cardiovascular disease in Noonan syndrome, HCM accounts for 20-30\%, while ASD (10-30\%), AVCD (5-15\%), VSD (5-10\%) are less common. Vascular anomalies, including mainly aortic dissection, aortic root dilation, or aneurysm of sinus of Valsalva, can be found in patients with NS $[21,22]$. Cardiovascular defects have some specific features.

\section{Pulmonary valve stenosis}

Pulmonary valve stenosis (PVS) is characterized by a dysplastic pulmonary valve with fibrous thickening of the annulus and the leaflets and could be associated with a 'supra-annular' stenosis, due to fusion 
of the valvular cusps with the wall of the pulmonary artery [20,21]. Intervention for this defect can then be surgical valvuloplasty, outflow tract patching or valve replacement; almost half of the individuals with NS need cardiac intervention. ASD, usually of the 'ostium secundum' type, is often in association with PVS. AVCD is generally partial and may be associated with subaortic stenosis or prolapse [22].

\section{Hypertrophic cardiomyopathy}

Besides asymmetrical septal thickening or concentric hypertrophy and decreased compliance ofleft ventricle, hypertrophiccardiomyopathy $(\mathrm{HCM})$ presents higher prevalence of reduced diastolic function and LV outflow tract obstruction than in non-syndromic patients. In addition, the onset of hypertrophic cardiomyopathy is earlier (median age 6 months) [12]. Myocardial ischemia due to reduced myocardial perfusion through the increased myocardial mass is common among patients with HCM, including young adolescents with RASopathies. Coronary arteries abnormalities (dilation of main left coronary artery, anterior descending artery or right coronary arteries) contribute to explain the higher risk of myocardial ischemia in these patients; other frequent manifestations of HCM in RASopathies are arrhythmias. Supraventricular and ventricular ectopic beats are common and nonsustained ventricular tachycardia is frequent and related to the risk for sudden cardiac death $[21,23]$. It must be noted that survival of patient affected by NS and HCM 15 years after diagnosis is lower (71\%) compared with those with NS without HCM (97\%), supporting the hypothesis that HCM in Noonan syndrome is an important risk factor for death. Significant diastolic dysfunction and associated cardiac alterations have been advocated as the main cause [1,23]. Cardiac involvement in NS is related to genotype-phenotype correlation: PVS is more common (approximately 70\%) in subjects with PTPN11 and SOS1 mutations, and it is less common (approximately 20\%) in patients with RAF1 lesions. HCM prevalence is relatively low in patients with PTPN11 or SOS1 mutations, but it is overrepresented in RAF1-associated Noonan syndrome (approximately 75\%). In patients carrying heterozygous RIT1 mutations, compared with the general NS population, the prevalence and severity of both HCM and CHD is higher [24].

\section{Genitourinary involvement}

About $10 \%$ of children with NS present renal abnormalities, the most common of which is dilatation of the renal pelvis. Less common abnormalities are duplex collecting systems, minor rotational anomalies, distal ureteric stenosis, renal hypoplasia, unilateral renal agenesis, unilateral renal ectopia and bilateral cysts with scarring are reported less commonly $[8,9]$. Delayed pubertal development is usually observed both in males and in females. Cryptorchidism is noted in $60 \%$ to $80 \%$ of males and subsequently deficient spermatogenesis may be associated; on the other hand, female patients present normal fertility. For this reason, the affected parent who transmits the disorder is predominantly the mother [25].

\section{Ocular and acoustic involvement}

About $95 \%$ of patients present some kind of ocular abnormalities. In addition to external ocular abnormalities (e.g. hypertelorism and eyelid anomalies), NS patients may be affected by strabismus, myopia, astigmatism, amblyopia, and/or limited ocular motility. Approximately $55 \%$ of patients have an abnormal ophthalmological test $[26,27]$. In NS hearing loss due to otitis media is a frequent complication; progressive high-frequency sensorineural hearing loss is also described. Even for avoiding speech delay, it is recommended to provide hearing assessment at diagnosis of NS [28,29].

\section{Lymphatic abnormalities}

Lymphatic anomalies are typical of NS. Dorsal limb lymphedema, localized on the top of the foot and back of the hand, is common. Intestinal, pulmonary, or testicular lymphatic vessels could be altered: there are reports of chylous effusions of the pleural space and/or peritoneum and localized lymphedema of the scrotum or vulva [30]. Moreover, it is important to note that prenatal features suggestive of NS are often of a lymphatic nature.

\section{Bleeding diathesis}

NS can be associated with an increased risk of bleeding and bruising, caused by a variety of bleeding abnormalities. Factor XI is the most frequently lacking, followed by factor XII and factor VIII, with some patients presenting multiple-factor deficiencies; widespread thrombocytopenia and platelet aggregation abnormalities were also reported $[31,32]$. Early studies showed that the prevalence of coagulation defects in NS was even $30 \%$, but several studies have highlighted that there is no strict correlation between coagulation study results and bleeding risk. In fact, NS patients with coagulopathy may show severe surgical haemorrhage as well as laboratory abnormalities with no clinical consequences. Anyway, since these patients undergo multiple surgeries (for example for cardiologic defects), it is important to regularly assess their bleeding risk [31-33].

\section{Risk of malignancies}

Predisposition to malignancy is an important concern in the prospective care of patients with RASopathies. In fact, the dysregulation of the RAS/MAPK signalling pathway typical of RASopathies is reported in the development of up to $20 \%$ of all sporadic hematologic and solid malignancies. Germline mutations appear to cause enhanced signalling activity although in a less robust way than in corresponding somatic mutations in genes underlying tumour formation. It is hypothesized that robustly activating somatic gene mutations causing cancer are not seen in germline RASopthies since they may cause embryonal lethality [34,35]. Both hematopoietic malignancies and malignant solid tumors were reported in association with NS. In a cohort of 632 individuals with molecularly confirmed NS, a childhood cancer standardized incidence ratio of 8.1 was described [34]. Among haematopoietic malignancies, the ones quite frequently reported include different types of leukaemia and lymphoma (Hodgkin's and Non-Hodgkin's types). Leukaemia is the most common malignancy associated with NS, germline PTPN11 mutation is described in most of cases. Specific mutations of PTPN11 or KRAS are associated with a myeloproliferative disorder (NS/MPD) resembling juvenile myelomonocytic leukaemia (JMML). NS/MPD occurs in neonates and infants, starts as a polyclonal disease and typically resolves over time. However, aggressive and monoclonal leukaemia that may be lethal have been reported [34,35]. Regarding malignant solid tumours, there are case reports of rhabdomyosarcomas, neuroblastomas, central nervous system tumours, testicular seminomas [36,37]. Costello syndrome is quite different than other RASopathies: it is characterized by solid tumour development in childhood and adolescence, but it is not associated with hematologic malignancies. Costello syndrome presents higher cancer risk than other RASopathies, especially for embryonal rhabdomyosarcoma, neuroblastomas, and early-onset bladder cancer. The cumulative incidence of cancer is $15 \%$ by age 20 years [35].

\section{Diagnosis}

NS is suspected clinically by observation of key features. Diagnostic criteria were developed by van der Burgt (2007): diagnosis is clinically 
Table 2. Diagnostic Criteria of Noonan Syndrome by van der Burgt [38].

\begin{tabular}{|l|l|l|}
\hline Features & A: Major & B: Minor \\
\hline 1: Facial & Typical face & Suggestive face \\
\hline 2: Cardiac & $\begin{array}{l}\text { Pulmonary valve stenosis and/or } \\
\text { hypertrophic cardiomyopathy }\end{array}$ & Other cardiac defects \\
\hline 3: Growth & $<3^{\circ}$ centile & $<10^{\circ}$ centile \\
\hline 4: Chest wall & Pectus excavates/carinatum & Broad thorax \\
\hline 5: Family history & $1^{\text {stdegree relative affected by NS }}$ & $1^{\text {stdegree suggestive of NS }}$ \\
\hline 6: Other & $\begin{array}{l}\text { Mild developmental delay, } \\
\text { cryptorchidism, AND lymphatic } \\
\text { dysplasia }\end{array}$ & $\begin{array}{l}\text { Mild developmental delay, } \\
\text { cryptorchidism, OR lymphatic } \\
\text { dysplasia }\end{array}$ \\
\hline
\end{tabular}

defined with Criterion $1 \mathrm{~A}+$ one of $2 \mathrm{~A}-6 \mathrm{~A} /$ two of $2 \mathrm{~B}-6 \mathrm{~B}$ or Criterion $1 \mathrm{~B}+$ two of $2 \mathrm{~A}-6 \mathrm{~A} /$ three of $2 \mathrm{~B}-6 \mathrm{~B}$ (Table 2) [38].

The diagnosis of NS is established by molecular genetic test. Usually it is performed using a multigene panel that includes pathogenetic genes; in order to distinguish NS from cardio-facial-cutaneous syndrome and Costello syndrome, most available panels include the genes for these diagnoses, too. Alternatively, serial single-gene testing (SGT) may be considered: SGT starting with PTPN11 would be the next best first test. Different serial single-gene testing can be chosen evaluating the individual phenotype. In $30 \%$ of cases, indeed, the responsible gene remains unknown. Anyway, the suitability and sequence of gene testing should be decided by a clinical geneticist. Prenatal testing is possible if the NS-related pathogenic variants have been identified in an affected family member. On the other hand, when a child is diagnosed with the syndrome the diagnosis of NS should be considered in parents $[12,39]$.

\section{Prenatal characteristics}

Cystic hygroma, skin oedema or nuchal translucency, pleural effusion and hydrops fetalis are frequently associated with NS in the prenatal period ( $50 \%$ of cases). These lymphatic system abnormalities were initially noted more than 20 years ago [40]. Polyhydramnios $(73 \%)$ is common and is associated with decreased foetal swallowing. Renal alterations, such as pelviectasis, hydronephrosis and increased kidney size, may be reported by prenatal ultrasound in about $20 \%$ of pregnancies [41]. It is difficult to identify cardiac involvement, including valvular dysplasia and hypertrophic cardiomyopathy: cardiac anomalies are diagnosed by foetal echocardiogram in $21 \%$ cases, while they are recognized in neonatal period in $80 \%$ of patients $[18,41,42]$. Anyway, these findings are nonspecific and may have different degrees of severity during pregnancy and among patients; therefore, the identification of prenatal echographic abnormalities, particularly those of lymphatic system, requires not only karyotyping, but also targeted organ screening, in order to distinguish NS from other congenital disease (e.g. other RASopathies) [42].

\section{Management}

In every child with NS, multidisciplinary evaluations are recommended in order to establish the extent of disease. Monitoring of anomalies found in any system is a paediatrician's responsibility. In 2010 Dyscerne, a European consortium, developed management guidelines for different age groups. They suggest that every infant with NS must be referred to dietary assessment, full cardiac evaluation and renal echographic evaluation; they also consider measures of weight, height and occipital circumference at birth and monthly in order to investigate short stature. At the diagnosis, they recommend visual screening and to provide hearing assessment in the 2nd half of first year. Concerning neuropsychological development and neurological involvement, patients should receive a developmental assessment in the 2nd half of first year [6,39]. During childhood, cardiac evaluation is necessary to rule out the onset of HCM: echocardiogram is carried out annually until the age of three and then at 5 and 10 years old and follow up is carried on in elderly ages, if no anomalies are shown. Concerning growth, using NS growth charts in childhood is critical: children with a height below the mean for NS should be referred to a paediatric endocrinologist. Moreover, during early childhood talipes should be screened and later scoliosis must be monitored. Coagulation system must be screened at least once during childhood and before any major surgery. It is necessary to carry on visual screening. In order to prevent speech development problems, hearing should be monitored once a year. At primary and secondary school entry neuropsychological assessment must be evaluated as well as intellectual/cognitive abilities; learning difficulties could be a result of motor delay, executive dysfunctions and inattention. Speech therapy, learning support and physiotherapy are fundamental tools. During adolescence, cardiac, neurological and skeletal follow-up must continue as well as specific attention to coagulation disorders and lymphoedema. Delayed puberty should be carefully evaluated. Moreover, patients should be referred for genetic counselling, mutation testing and discussion of risks to children as well as options in pregnancy at an appropriate time [6,39]. The multitude of haematologic and solid malignancies reported in association with the RASopathies requires special clinical awareness for malignancy screening. Patients with these disorders should be evaluated for the presence of specific types of tumors reported with higher frequency in this population (such as leukaemia, lymphoma, neuroblastoma, rhabdomyosarcoma, brain tumours, and bladder carcinoma) depending on clinical symptoms, examination, and laboratory findings. The lack of large cohort studies estimating the prevalence of tumors in these patients has complicated the establishment of specific screening protocols in those disorders, anyway recommendations for cancer surveillance in individuals with RASopathies have been published [35]. Since patients with RASopathies have mildly increased cancer risk, increased awareness and prompt assessment are necessary, while routine cancer surveillance is considered excessive in most cases. In patients with NS due to specific PTPN11 or KRAS mutations known to be associated with MPD/JMML, 3 to 6 monthly physical exams with spleen size assessment and complete blood counts with differential should be considered starting at birth (or diagnosis) and continuing until the age of 5 years [35].

\section{Treatment}

There is no single treatment for NS, but it is possible to treat many aspects of the condition. Treatment of different manifestations in NS is standard: it does not differ from treatment in the general population, even for cardiologic management. On this issue, it is important to remind that patients undergoing percutaneous balloon pulmonary valvuloplasty have a high re-intervention rate $(65 \%)$ for residual valvular pulmonary stenosis. As regards HCM in NS, medical therapy (beta-blockers, disopyramide or calcium channel blockers (L-type) is the usual initial treatment, while a determining factor for considering invasive treatment occurs with a $50 \mathrm{mmHg}$ or greater gradient trough the LV outflow tract. Other factors to consider include the presence of subaortic stenosis (accessory fibrous connective tissue), abnormal insertion off the mitral valve, anomalous papillary muscles, mitral leaflet length anomaly, and mitral chordal attachments, all of which may be present in Noonan syndrome patients. Taking these factors into consideration, surgical myectomy can be utilized in Noonan syndrome with symptomatic HCM of an obstructive nature [23].

Anyway, the most concerning and debated aspect in NS treatment is growth hormone therapy. Recombinant human growth hormone 
(rhGH) is widely used for the treatment of short stature across several disorders, primarily with the aim of improving linear growth toward the normal adult range. The causes of short stature in NS are multifactorial and not completely clarified. Growth hormone deficiency, GH insensitivity, and neurosecretory dysfunction have been investigated in these patients [43-46]. rhGH (Norditropin) is licensed in the USA, Switzerland, South Korea, Israel, Brazil and the Philippines for the treatment of children with short stature due to Noonan syndrome, at doses of up to $0.066 \mathrm{mg} / \mathrm{kg} /$ day, whereas $\mathrm{GH}$ is not approved for this indication in Europe [43-47]. Some studies were performed to evaluate the effects of rhGH treatment in NS. For example, a Korean group enrolled 15 prepubertal NS children who received rhGH (50-75 microg $/ \mathrm{kg} /$ day for 6 days a week for 3 years) and analysed pre and post treatment height, weight, bone age, IGF1 and IGFBP3 levels. They found increased height standard deviation score and serum IGF1 levels in all patients, while they noted a decreased response to rhGH in patients with PTPN11 mutations [48]. Furthermore, a Japanese randomized double-blind multicenter trial evaluated the effects of rhGH therapy in children with NS. Prepubertal children were treated with rhGH at two different doses $0.033 \mathrm{mg} / \mathrm{kg} /$ day and $0.066 \mathrm{mg} / \mathrm{kg} /$ day for 104 weeks; this study reported an increased height standard deviation scores and IGF1 levels for both doses, with greater improvement in patients who received the higher dose. No significant changes in glucose profiles and electrocardiogram or echocardiography findings were described [49]. rhGH treatment was evaluated by a Turkish group, registering retrospectively growth in NS patients with or without rhGH treatment. HSDS of NS patients significantly increased during rhGH treatment, particularly HSDS increased by $0.4 \pm 0.44$ SD during the first year of treatment, and total increments were $0.75 \pm 0.55 \mathrm{SD}$ and $0.76 \pm 0.41 \mathrm{SD}$ at the end of the second and third years of treatment. Instead HSDS of patients without rhGH therapy did not change during follow-up [50]. Even if short and long-term studies have demonstrated the effectiveness of rhGH therapy in NS, traditionally there is concern about rhGH effects on cardiac involvement and tumoral progression. Some studies reported no significant adverse events of rhGH therapy regarding progression of hypertrophic cardiomyopathy, alteration of metabolism and tumour development [51-53]. Several studies showed that blood glucose levels remain within normal ranges during rhGH therapy. As regards to cardiac involvement, there was no evidence of increasing ventricular wall thickness: a prospective rhGH trials of over 3 years showed that no children with NS experienced any serious complication of heart based on echocardiography [13]. Data on rhGH and tumour risk give no cause for concern, but small patient numbers and few documented cases prevent risk assessment [54]. Currently, there are two non-interventional multicentre studies assessing the effectiveness and safety of somatropin (Norditropin, particularly): the NordiNet International Outcome Study (NordiNet IOS; NCT00960128) and the American Norditropin Studies: Web-Enabled Research Program (ANSWER; NCT01009905). They enrolled patients with GH deficiency, Turner syndrome, Noonan syndrome, idiopathic short stature, PraderWilli syndrome, or born small for gestational age, who started rhGH treatment aged $<1$ year. In NordiNet 154 NS patients underwent full statistical analysis used to evaluate safety outcomes, while in ANSWER more than 250 NS patients were enrolled. The most frequent events across indications were those commonly observed in children treated with rhGH and included headache, injection-site reactions, oedema, and arthralgia. No new safety signals of concern were noted in any of the indications, including NS, providing reassurance on the long-term safety of rhGH treatment. Anyway, it has been suggested that treating patients with pre-existing risk factors for diabetes and malignancy (like those with NS) with caution and monitoring regularly during follow-up
[55,56]. In summary, there is no current indication to rhGH treatment in NS in European countries, even if it is widely used in clinical trials and practice all over Europe, given its safety outcomes.

\section{Conclusions}

NS represents the paradigm of RASopathies, e.g. a heterogeneous group of genetically transmitted disorders of RAS-MAPK signalling pathway. Historical identification was based on the triad typical face, short stature and cardiac involvement. Nowadays, specific phenotype and molecular bases of disease are well recognized; in fact, several pathogenetic gene mutations have been discovered. Prompt diagnosis is made possible by the knowledge of clinical features and it is confirmed by genetic tests. Moreover, a proper awareness of NS should prompt general paediatricians and paediatric endocrinologists to care affected children throughout their growth. Usually, the main concerns about treatment relate cardiac surgery and outcome and safety of rhGH therapy. To date, cardiac approach is the same of general population, even if overall outcome in NS is worse when several cardiac abnormalities are present. As regards to rhGH safety, several studies showed no progression of cardiac involvement and metabolic disturbances or even increased tumoral incidence. Up until today, hormone replacement therapy is approved in US, but not in Europe, though this may change in the future and influence daily management of NS patients by the general paediatricians.

\section{Authorship}

GD and FC contributed equally to writing the manuscript.

\section{References}

1. Tartaglia M, Mehler EL, Goldberg R, Zampino G, Brunner HG, et al. (2001) Mutations in PTPN11, encoding the protein tyrosine phosphatase SHP-2, cause Noonan syndrome. Nat Genet 29: 465-468. [Crossref]

2. Tajan M, Paccoud R, Branka S, Edouard T, Yart A (2018) The RASopathy Family: Consequences of Germline Activation of the RAS/MAPK Pathway. Endocr Rev 39: 676-700. [Crossref]

3. Wright EM, Kerr B (2010) RAS-MAPK pathway disorders: important causes of congenital heart disease, feeding difficulties, developmental delay and short stature. Arch Dis Child 95: 724-730. [Crossref]

4. Mendez HM, Opitz JM (1985) Noonan syndrome: a review. Am J Med Genet 21: 493 506. [Crossref]

5. Tartaglia M, Cordeddu V, Chang H (2004) Paternal germline origin and sex-ratio distortion in transmission of PTPN11 mutations in Noonan syndrome. Am J Hum Genet 75: 492-497. [Crossref]

6. Bouchikhi IE, Belhassan K, Moufi F (2016) Noonan syndrome-causing genes Molecular update and an assessment of the mutation rate. Int J Pediatr Adolesc Med 3: 133-142. [Crossref]

7. Bellio M, Garcia C, Edouard T (2019) Catalytic dysregulation of SHP2 leading to Noonan syndromes impacts on platelet signalling and functions. Blood 134: 23042317. [Crossref]

8. Online Mendelian Inheritance in Man, OMIM ${ }^{\circledR}$. Johns Hopkins University, Baltimore, MD. 2019. https://omim.org MIM Number: 163950. Available at https://omim.org/ [Accessed 23 December 2019]

9. Sharland M, Burch M, McKenna WM, Paton MA (1992) A clinical study of Noonan syndrome. Arch Dis Child 67: 178-183. [Crossref]

10. Kruszka P, Porras AR, Addissie YA, Moresco A, Medrano S, et al. (2017) Noonan syndrome in diverse populations. Am J Med Genet A 173: 2323-2334. [Crossref]

11. Allanson JE, Roberts AE (2001) [Updated 2019 Aug 8]. Noonan Syndrome GeneReviews ${ }^{\circledR}$ Adam MP, Ardinger HH, Pagon RA, Wallace SE, Bean LJH, Stephens K, Amemiya A, editors. GeneReviews ${ }^{\circledR}$ [Internet]. Seattle (WA): University of Washington, Seattle; 1993-2020.

12. Romano AA, Allanson JE, Dahlgren J (2010) Noonan syndrome: Clinical features, diagnosis, and management guidelines. Pediatrics 126: 746-759. 
13. Noordam C (2009) Growth hormone and the heart in Noonan syndrome. Horm Res 72 Suppl 2: 49-51. [Crossref]

14. Malaquias AC, Noronha RM, Souza TTO (2019) Impact of Growth Hormone Therapy on Adult Height in Patients with PTPN11 Mutations Related to Noonan Syndrome. Horm Res Paediatr 91: 252-261. [Crossref]

15. De Rocca Serra-Nédélec A, Edouard T, Tréguer K (2012) Noonan syndrome-causing SHP2 mutants inhibit insulinlike growth factor 1 release via growth hormone-induced ERK hyperactivation, which contributes to short stature. Proc Natl Acad Sci 109: 42574262. [Crossref]

16. Cessans C, Ehlinger V, Arnaud C (2016) Growth patterns of patients with Noonan syndrome: correlation with age and genotype. Eur J Endocrinol 174: 641-650. [Crossref]

17. Pierpont E I (2016) Neuropsychological Functioning in Individuals with Noonan Syndrome: A Systematic Literature Review with Educational and Treatment Recommendations. J Pediatr Neuropsychol 2: 14-33.

18. Croonen EA, Essink M, van der Burgt I, Draaisma JM, Noordam C, et al. (2017) Motor performance in children with Noonan syndrome. Am J Med Genet A 173: 2335-2345. [Crossref]

19. Garg S, Brooks A, Burns A (2017) Autism spectrum disorder and other neurobehavioral comorbidities in rare disorders of the Ras/MAPK pathway. Dev Med Child Neurol 59: 544-549. [Crossref]

20. Roberts AE, Allanson JE, Tartaglia M, Gelb BD (2013) Noonan syndrome. Lancet 381: 333-342. [Crossref]

21. Calcagni G, Adorisio R, Martinelli S, Grutter G, Baban A, et al. (2018) Clinical Presentation and Natural History of Hypertrophic Cardiomyopathy in RASopathies. Heart Fail Clin 14: 225-235. [Crossref]

22. Prendiville TW, Gauvreau K, Tworog-Dube E, Patkin L, Kucherlapati RS, et al. (2014) Cardiovascular disease in Noonan syndrome. Arch Dis Child 99: 629-634. [Crossref]

23. Hickey EJ, Mehta R, Elmi M (2011) Survival implications: Hypertrophic cardiomyopathy in Noonan syndrome. Congenit Heart Dis 6: 41-47. [Crossref]

24. Calcagni G, Digilio M, Marino B, Tartaglia M (2019) Pediatric patients with RASopathy-associated hypertrophic cardiomyopathy: the multifaceted consequences of PTPN11 mutations. Orphanet J Rare Dis 14: 14-17. [Crossref]

25. Noonan JA (2006) Noonan syndrome and related disorders: Alterations in growth and puberty. Rev Endocr Metab Disord 7: 251-255. [Crossref]

26. Van Trier DC (2018) Ocular findings in Noonan syndrome: a retrospective cohort study of 105 patients. European J Pediatr 177: 1293-1298. [Crossref]

27. Reynolds DJ, Rubin SE, Fox J, Kodsi SR (2004) Ocular manifestations of Noonan syndrome in the pediatric patient. J AAPOS 8: 282-283. [Crossref]

28. van Nierop JWI, van Trier DC, van der Burgt I, Draaisma JMT, Mylanus EAM, et al. (2017) Cochlear implantation and clinical features in patients with Noonan syndrome and Noonan syndrome with multiple lentigines caused by a mutation in PTPN11. Int $J$ Pediatr Otorhinolaryngol 97: 228-234. [Crossref]

29. Li X, Yao R, Tan X, Li N, et al. (2019) Molecular and phenotypic spectrum of Noonan syndrome in Chinese patients. Clin Genet 96: 290-299. [Crossref]

30. Joyce S, Gordon K, Brice G (2016) The lymphatic phenotype in Noonan and Cardiofaciocutaneous syndrome. European J Hum Genet 24: 690-696. [Crossref]

31. Shaw AC, Kalidas K, Crosby AH, Jeffery S, Patton MA (2007) The natural history of Noonan syndrome: a long-term follow-up study. Arch Dis Child 92: 128-132. [Crossref]

32. Artoni A, Selicorni A, Passamonti SM, et al. 2014. Hemostatic abnormalities in Noonan syndrome. Pediatrics 133: e1299-1304. [Crossref]

33. Nugent DJ, Romano AA, Sabharwal S, Cooper DL (2019) Evaluation of bleeding disorders in patients with Noonan syndrome: A systematic review. J Blood Med 9: 185-192. [Crossref]

34. Kratz CP, Franke L, Peters H (2015) Cancer spectrum and frequency among children with Noonan, Costello, and cardio-facio-cutaneous syndromes. British J Cancer 112: 1392-1397. [Crossref]

35. Villani A, Greer MLC, Kalish JM (2017) Recommendations for cancer surveillance in individuals with RASopathies and other rare genetic conditions with increased cancer risk. Clin Cancer Res 23: e83-e90. [Crossref]

36. Jongmans MC, Hoogerbrugge PM, Hilkens L (2010) Noonan syndrome, the SOS1 gene and embryonal rhabdomyosarcoma. Genes Chromosomes Cancer 49: 635-641. [Crossref]
37. Garavelli L, Cordeddu V, Errico S, Bertolini P, Street ME, et al. (2015) Noonan syndrome-like disorder with loose anagen hair: a second case with neuroblastoma. $\mathrm{Am}$ J Med Genet A 167A: 1902-1907. [Crossref]

38. van der Burgt I (2007) Noonan syndrome. Orphanet J Rare Dis 2: 4. [Crossref]

39. DYSCERNE Noonan Syndrome Guideline Development Group. 2010. Management of Noonan syndrome. A clinical guideline. Available at https://rasopathiesnet.org [Accessed 15 December 2019]

40. Bromley B, Miller W, Foster S, Benacerraf B. 1991. The prenatal sonographic features of Kniest syndrome. J Ultrasound Med 10: 705-707. [Crossref]

41. Myers A, Bernstein J A, Brennan M L (2014) Perinatal features of the RASopathies: Noonan syndrome, Cardiofaciocutaneous syndrome and Costello syndrome. Am J Med Genet 164: 2814-2821. [Crossref]

42. Menashe M, Arbel R, Raveh D, Achiron R, Yagel S (2002) Poor prenatal detection rate of cardiac anomalies in Noonan syndrome. Ultrasound in Obstet Gynecol 19: 51-55. [Crossref]

43. Romano A, Blethen L, Dana K, Noto R (1998) Growth hormone treatment in Noonan syndrome: the national Cooperative Growth study experience. Pediatrics 128: s18-21. [Crossref]

44. Tanaka K, Sato A (1992) Noonan syndrome presenting growth hormone neurosecretory dysfunction. Int Med 31: 908-911. [Crossref]

45. Binder G, Neuer K, Ranke MB, Wittekindt NE (2005) PtPn11 mutations are associated with mild growth hormone resistance in individuals with Noonan syndrome. $J$ Clin Endocrinol Metab 90: 5377-5381. [Crossref]

46. Padidela R, Camacho-Hübner C, Attie KM, Savage MO (2007) Abnormal growth in Noonan syndrome: genetic and endocrine features and optimal treatment. Horm Res 70: 129-136. [Crossref]

47. European Medicines Agencies (2012) Somatotropin. Available at https://www.ema europa.eu/en/medicines/human/referrals/somatropin [Accessed 30 December 2019]

48. Jeong I, Kang E, Cho JH, Kim GH, Lee BH, et al. (2016) Long-term efficacy of recombinant human growth hormone therapy in short-statured patients with Noonan syndrome. Ann Pediatr Endocrinol Metab 21: 26-30. [Crossref]

49. Ozono K, Ogata T, Horikawa R, Matsubara Y, Ogawa Y, et al. (2018) Efficacy and safety

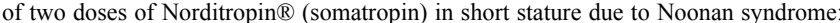
a 2-year randomized, double-blind, multicenter trial in Japanese patients. Endocr J 65: 159-174. [Crossref]

50. Şıklar Z, Genens M, Poyrazoğlu Ş (2016) The growth characteristics of patients with Noonan syndrome: Results of three years of growth hormone treatment: A nationwide multicenter study. J Clin Res Pediatr Endocrinol 8: 305-312. [Crossref]

51. Lee PA, Ross JL, Pedersen BT, Kotnik P, Germak JA, Christesen HT (2015) Noonan syndrome and Turner syndrome patients respond similarly to 4 years' growth-hormone therapy: longitudinal analysis of growth-hormone-naïve patients enrolled in the NordiNet ${ }^{\circledR}$ International Outcome Study and the ANSWER Program. Int $J$ Pediatr Endocrinol 1: 1-9. [Crossref]

52. Pfäffle R (2015) Hormone replacement therapy in children: The use of growth hormone and IGF-I. Best Pract Res Clin Endocrinol Metab 29: 339-352. [Crossref]

53. Seo GH, Yoo HW (2018) Growth hormone therapy in patients with Noonan syndrome. Ann Pediatr Endocrinol Metab 23: 176-181. [Crossref]

54. Noonan JA, Kappelgaard AM (2015) The efficacy and safety of growth hormone therapy in children with noonan syndrome: a review of the evidence. Horm Res Paediatr 83: 157-166. [Crossref]

55. Lee P A, Ross J, Germak J A, Gut R (2012) Effect of 4 years of growth hormone therapy in children with Noonan syndrome in the American Norditropin Studies: Web-Enabled Research (ANSWER) Program ${ }^{\circledR}$ registry. Int J Pediatr Endocrinol 1: 1-8. [Crossref]

56. Savendahl L, Polak M, Backeljauw P, Blair J, Miller BS, et al. (2019) Treatment of Children With GH in the United States and Europe: Long-Term Follow-Up From NordiNet ${ }^{\circledR}$ IOS and ANSWER Program. J Clin Endocrinol Metab 104: 4730-4742. [Crossref]

Copyright: (C2020 Dodi G. This is an open-access article distributed under the terms of the Creative Commons Attribution License, which permits unrestricted use, distribution, and reproduction in any medium, provided the original author and source are credited. 